\title{
Growth of Literature and Measures of Scientific Productivity of Indian Chemical Science Research during 2002-2016
}

\author{
M. Chaman Sab*, P. Dharani Kumar, B.S. Biradar \\ Department of Library \& Information Science, Kuvempu University, Shankaraghatta - 577 451, Karnataka, India.
}

\section{ART ICLE DETAILS}

Article history:

Received 11 January 2018

Accepted 29 January 2018

Available online 05 February 2018

\section{Keywords:}

Chemical Science

Scientometrics

Scientific Productivity

\begin{abstract}
A B S T R A C T
This study reports the data analysis of chemical science research World and India during 2002-2016. Different data sets have been used for application of different indicators, publications, growth rate, areas of research and discussing its media of communication, strength and weakness in the areas of research, quality of research output, nature of highly cited papers, collaboration (national and international). The analysis of chemical science has finds the publications share of India during 2002-2016 was 5.46\%, which has increased from 3.94 in 2002 to 6.99 in 2016 and it is observed from the study that the percentage of India's papers compared to that of the world's papers. India's share of science and technology research output increased from $3.94 \%$ in 2002 to $6.99 \%$ in 2016 . The study shows a significant increase and suggests a $5.30 \%$ average growth in the yearly share and data has been collected from Web of Science database.
\end{abstract}

\section{Introduction}

Scientometrics' is the branch science of science that describes the output traits in terms of organizational research structure, resource inputs and outputs, develops benchmarks to evaluate the quality of information output. Scientometric research publications are a quantitative measure for the basic research activity in a country. Scientometrics is one of the most important measures for the assessment of scientific productions. There are many definitions for the term 'Scientometrics' in the literature; Scientometrics is the quantitative study of the disciplines of science based on published literature and communication [1]. At present the scientometrics study is one of the truly interdisciplinary research fields extended to almost all scientific fields. Scientometrics applications are used to measure scientific activities, mainly by producing statistics on scientific publications indexed in databases [2]

The field of library and information science (LIS) has developed several quantitative methods to study the various aspects of subjects. The metrics of LIS are continuously increasing, starting from librametrics, bibliometrics, scientometrics, informatics, webometrics, netometrics to cybernetics [3]. The study intends to explore the blueprints of scholarly communication of Indian chemical science for the period 2002 to 2016 and determine to exposure the quality of contributions.

The generation of new scientific and technical knowledge/information has been accelerating over the past several years. In recent years an increasing attention has been paid to the social dimensions of scientific community that produces sciences. But this unprecedented growth in literature has become a major concern for the scientists, scholars, and library professional as they try to keep themselves abreast with new advances in their subject, and information professionals try to organize this knowledge. How the growth, origin and language of literature reflect in various national level activities in $\mathrm{R} \& \mathrm{D}$ is a matter of great concern to the managers of the scientific activities in government industry and in academic community.

The word 'growth' refers to an increase, expansion in actual size, implying a 'change of state'. Change in size of literature over a specific period of time is termed as 'growth of literature'. A systematic study of the increase in scientific literature, scientific community and institutions etc. facilitates quantitative and qualitative understanding of science and various scientific phenomena. In the recent past, studies dealing with the assessment of scientific research in chemical science by different nations

*Corresponding Author : chamansabm@gmail.com(M. Chaman Sab) have been reported in this study. The present study seeks to assess the contribution of major countries as reflected by the coverage of publications in web of science database during 2002 to 2016.

The past decade has witnessed the modern advances of highthroughput technology and rapid growth of research capacity in producing large-scale biological data, both of which were concomitant with an exponential growth of chemical science literature. This wealth of scholarly knowledge is of significant importance for researchers in making scientific discoveries and healthcare professionals in managing healthrelated matters. However, the acquisition of such information is becoming increasingly difficult due to its large volume and rapid growth. In response, the web of science and other citation databases are continuously making changes to their web service for improvement to help users in quick and efficient search and retrieval of relevant publications [4].

Velmurugan [5] has studied the research output of 203 articles published in Annals of Library and Information Studies journal for a period 2007-2012, It was found that the most of the contributions are by two authored papers i.e., 88 (43.35\%). The degree of collaboration ranges from 0.57 to 0.82 and the average degree of collaboration is 0.64 . Thanuskodi [6] has examined the research output of social science subjects, study covers year-wise, institution-wise, country-wise, authorship pattern, range of references cited of the articles etc. Kumar et al. [7] analysed the growth and development of bibliometric and scientometric research in the field of physics and engineering and data has been retrieved from INSPEC Database during 1999-2008. It found that the authorship and collaboration trend was towards multi-authored papers. Guan \& Ma [8] have observed the China's Semiconductor Literature and found mega authored papers records that show higher value for coauthorship index. Patra et al. [9] have explored the growth pattern, core journals and authors' distribution in the field of bibliometric using data from Library and Information Science Abstract (LISA) and found that the growth of literature does not show any definite pattern. Kannappanavar et al. [10] have analysed the publishing trends of Indian Chemical Scientists during 1996-2000, which shown average number of authors per paper has increased from 7.52 to 8.39 .

The main objective of the study is to present the growth of literature and make the quantitative assessment of status of chemical science research in India by way of analyzing the following features of research output, to find out year-wise growth of publications, the domain-wise contributions, language-wise distribution of publications, the channels of communications used by the scientists, collaboration pattern in the publications, the extent of international collaboration, and source-wise distribution of journals. 


\section{Experimental Methods}

The data for the present study were retrieved from ISI Web of Science database (including Science Citation Index (SCI), Social Science Citation Index (SSCI) and Arts \& Humanities Citation Index (AHCI)). The data are extracted from Web of Science on $21^{\text {st }}$ April, 2017. By using suitable search syntax, the data has been downloaded for the period 2002-2016. The collected data were analysed using MS-Excel Spreadsheet and MS-Word.

\section{Results and Discussion}

\subsection{Status and Growth of World Chemical Science Literature}

It could be clearly observed from the Table 1, the research output of India and Average Citations per Papers of India. India has produced $1,31,212$ papers, and received $12,70,317$ citations during the period 20022016, Average Citations per Paper is 9.68. As per the Web of Science data, the cumulative publications growth of chemical science research output of India had increased from 27,613 publications during 2002-2006 to 41,693 publications during 2007-2011, and 61,915 publications during 20122016.

India has produced the highest publication i.e. 13,544 papers in 2016. The lowest publication is 4,522 in 2002. Chemical science publications are gradually increased year by year, the publications share of chemical science which has increased from 3.94\% in 2002 to $6.99 \%$ in 2016. According to the research the trend line shows that there is a steady and significant increase in the publications in chemical science (Fig. 1). India's publications are gradually increased year by year. The global publications share of India during 2002-2016 was 5.46\%, which has increased from 3.94 in 2002 to 6.99 in 2016.

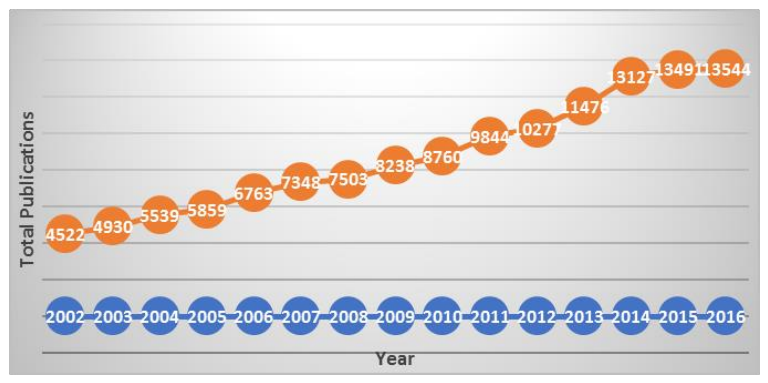

Fig. 1 Indian Research output in chemical science

Table 1 Status of World and Indian Chemical science Literature

\begin{tabular}{llllllll}
\hline WORLD & \multicolumn{7}{c}{ INDIA } \\
\hline Year & TP & $\%$ & TP & TC & ACPP & H-index & TP Share \\
\hline 2002 & 114912 & 4.78 & 4522 & 94726 & 20.95 & 105 & 3.94 \\
2003 & 122020 & 5.08 & 4930 & 102072 & 20.7 & 113 & 4.04 \\
2004 & 129479 & 5.39 & 5539 & 120603 & 21.77 & 114 & 4.28 \\
2005 & 135085 & 5.62 & 5859 & 126800 & 21.64 & 122 & 4.34 \\
2006 & 145318 & 6.04 & 6763 & 138815 & 20.53 & 127 & 4.65 \\
2007 & 147836 & 6.15 & 7348 & 142009 & 19.33 & 119 & 4.97 \\
2008 & 153488 & 6.38 & 7503 & 131716 & 17.56 & 112 & 4.89 \\
2009 & 158723 & 6.60 & 8238 & 138103 & 16.76 & 110 & 5.19 \\
2010 & 158913 & 6.61 & 8760 & 135258 & 15.44 & 109 & 5.51 \\
2011 & 174805 & 7.27 & 9844 & 140215 & 14.24 & 100 & 5.63 \\
2012 & 182690 & 7.60 & 10277 & NA & NA & NA & 5.63 \\
2013 & 191773 & 7.98 & 11476 & NA & NA & NA & 5.98 \\
2014 & 203848 & 8.48 & 13127 & NA & NA & NA & 6.44 \\
2015 & 191732 & 7.97 & 13491 & NA & NA & NA & 7.04 \\
2016 & 193822 & 8.06 & 13544 & NA & NA & NA & 6.99 \\
$2002-06$ & 646814 & 26.90 & 27613 & 583016 & 21.11 & NA & 4.27 \\
$2007-11$ & 793765 & 33.01 & 41693 & 687301 & 16.48 & NA & 5.25 \\
$2012-16$ & 963865 & 40.09 & 61915 & NA & NA & NA & 6.42 \\
$2002-16$ & 2404444 & & 131221 & 1270317 & 9.68 & NA & 5.46 \\
\hline
\end{tabular}

$T P=$ Total Papers; $A C P P=$ Average Citations per Paper, $N A=$ Not available

The global research output in chemical science has increased from $1,14,912$ in 2002 to $1,93,822$ in 2016 . World's publications had increased from $6,46,814$ publications during 2002-2006 to 7,93,765 publications during 2007-2011, and 9,63,865 publications during 2012-2016. In the same manner, the Indian research output in chemical science too has increased from 4,522 in 2002 to 13,544 by 2016 (Table 2).

It is observed from the study that the above point gets clarified when we analyse the percentage of India's papers compared to that of the world's papers. India's share of science and technology research output increased from $3.94 \%$ in 2002 to $6.99 \%$ in 2016 . The plot shows a significant increase and the trend suggests a $5.30 \%$ average growth in the share per annum in the study period.

Table 2 Growth of Indian Research output in chemical science

\begin{tabular}{lll}
\hline Year & TP & \% of TP Share \\
\hline 2002 & 4522 & 3.94 \\
2003 & 4930 & 4.04 \\
2004 & 5539 & 4.28 \\
2005 & 5859 & 4.34 \\
2006 & 6763 & 4.65 \\
2007 & 7348 & 4.97 \\
2008 & 7503 & 4.89 \\
2009 & 8238 & 5.19 \\
2010 & 8760 & 5.51 \\
2011 & 9844 & 5.63 \\
2012 & 10277 & 5.63 \\
2013 & 11476 & 5.98 \\
2014 & 13127 & 6.44 \\
2015 & 13491 & 7.04 \\
2016 & 13544 & 6.99 \\
$2002-2006$ & 27613 & 4.27 \\
$2007-2011$ & 41693 & 5.25 \\
$2012-2016$ & 61915 & 6.42 \\
$2002-2016$ & 131221 & 5.46 \\
\hline
\end{tabular}

\subsection{Relative Growth Rate and Doubling Time}

The table also represents the chronological distribution, Relative Growth Rate (RGR is the growth rate relative to the size of population or continuous growth rate with reference to scientific literature publication time, Relative Growth Rate (GR) is the increase in the number of publications per unit time) and Doubling Time (The doubling time (Dt) is the given period required for quantity to double in size or value) of world publications in the field of chemical science during the period 2002-2016.

One of the obvious features of scientific literature in recent years has been its rate of growth. A number of growth models have been proposed regarding the rate of growth. Price (1963) proposed an exponential rate of growth of scientific literature. He predicted a regular exponential growth with doubling period of ten to fifteen years.

\subsubsection{World and India}

The total output of world and India has been shown in Table 3 (fifteen year) (Figs. 2-5) along with the growth rate and doubling time. The table shows that the relative growth rate of world output decreases gradually from 0.72 to 0.02 in fifteen year's period (2002-2016). The reason for this growth due to the information communication technology and World Wide Web. The doubling time $\left(\mathrm{D}_{\mathrm{t}}\right)$ correspondingly increases from 0.96 to 8.25 in this period. The mean growth rate and doubling time for the world is 1.13 and 1.17 respectively.

Indian output, as shown in Table 3 , the growth rate decreases gradually from 0.74 to 0.11 during fifteen years period (2002-2016). This growth may be due to the establishment of major scientific institutions like DST, CSIR, NPL, NCL, etc., which resulted into more scientific research in chemical science. Correspondingly, the doubling time increases from 0.94 to 6.36 in the same period. The mean growth rate and doubling time for Indian output is 0.12 and 0.93 .

But the year-wise analysis of growth rate and doubling time for world and India indicates a different finding. The growth rate of World is comparatively more than that of India. The average growth rate of world and India is 0.22 and 0.24 respectively. Correspondingly, the doubling time of world is 4.58 and India is 3.83 respectively.

Table 3 Relative Growth Rate and doubling time of World and India

\begin{tabular}{lllllll}
\hline Year & World Output & RGR & Dt & India Output & RGR & Dt \\
\hline 2002 & 114912 & & & 4522 & & \\
2003 & 122020 & 0.72 & 0.96 & 4930 & 0.74 & 0.94 \\
2004 & 129479 & 0.44 & 1.59 & 5539 & 0.46 & 1.50 \\
2005 & 135085 & 0.31 & 2.21 & 5859 & 0.33 & 2.10 \\
2006 & 145318 & 0.25 & 2.72 & 6763 & 0.28 & 2.47 \\
2007 & 147836 & 0.21 & 3.37 & 7348 & 0.24 & 2.94 \\
2008 & 153488 & 0.18 & 3.92 & 7503 & 0.19 & 3.56 \\
2009 & 158723 & 0.15 & 4.48 & 8238 & 0.18 & 3.91 \\
2010 & 158913 & 0.13 & 5.17 & 8760 & 0.16 & 4.35 \\
2011 & 174805 & 0.13 & 5.36 & 9844 & 0.15 & 4.52 \\
2012 & 182690 & 0.12 & 5.80 & 10277 & 0.14 & 5.01 \\
\hline
\end{tabular}




\begin{tabular}{lllllll}
\hline 2013 & 191773 & 0.11 & 6.21 & 11476 & 0.13 & 5.14 \\
2014 & 203848 & 0.11 & 6.51 & 13127 & 0.13 & 5.15 \\
2015 & 191732 & 0.09 & 7.64 & 13491 & 0.12 & 5.69 \\
2016 & 193822 & 0.08 & 8.25 & 13544 & 0.11 & 6.36 \\
Mean & & 1.13 & 1.17 & & 0.12 & 0.93 \\
\hline
\end{tabular}

RGR = Relative Growth Rate; $D t=$ Doubling Time

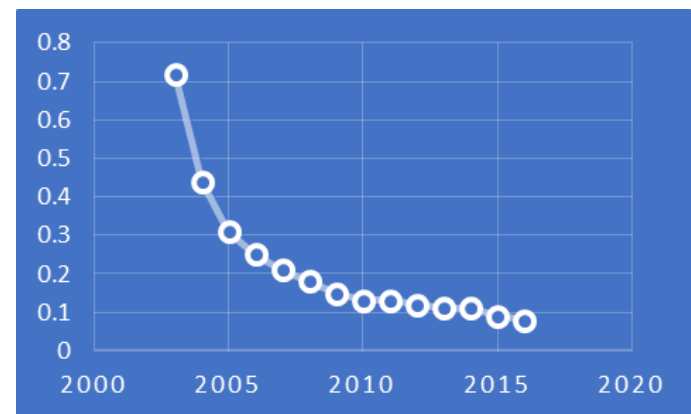

Fig. 2 Realtive Growth Rate (RGR) of world

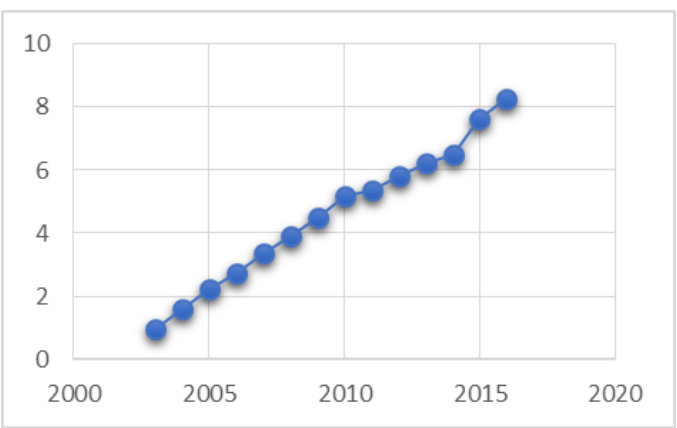

Fig. 3 Doubling Time (Dt) of world

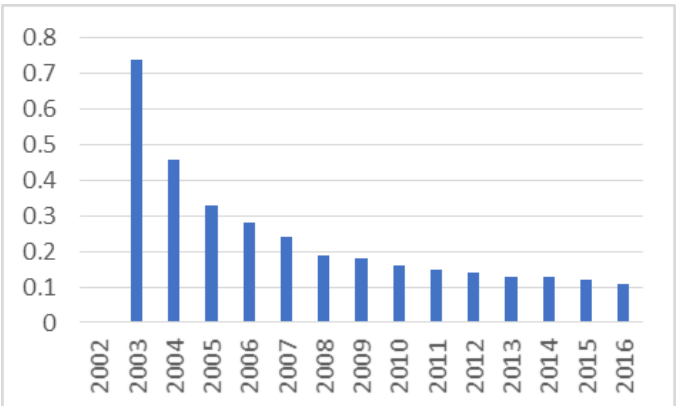

Fig. 4 Realtive Growth Rate (RGR) of India

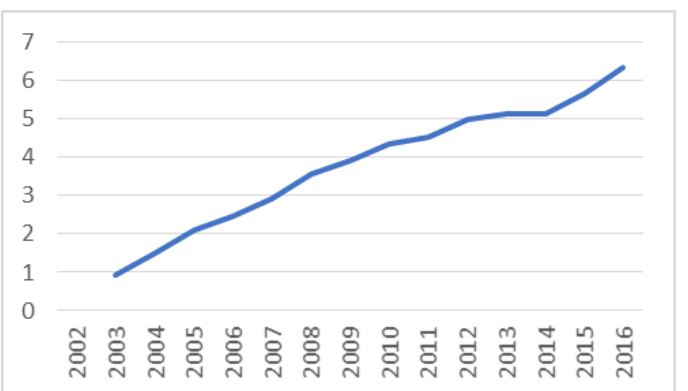

Fig. 5 Doubling Time (Dt) of India

\subsection{Most Productive Authors in Indian Chemical Science Research}

The table shows the highly productive authors from Indian chemical science research output during the study period. The top 25 authors having been identified as most productive authors in Indian chemical science research, the publications profile of these 25 authors along with their research output, citations received and h-index values are presented in Table 4 . These 25 authors together contributed 21,257 papers with an average of 817.58 papers per author and account for $16.20 \%$ share in the cumulative Indian publications output during 2002-2016.
Table 4 Most productive authors in Indian Chemical Science Research

\begin{tabular}{|c|c|c|c|c|c|c|c|}
\hline Sl. No. & Authors & Affiliation & TP & $\begin{array}{l}\% \text { of } \\
131221\end{array}$ & TC & ACP & H-index \\
\hline 1 & Kumar, A. & $\begin{array}{l}\text { National University of } \\
\text { Singapore, Department } \\
\text { of Chemical \& Bio } \\
\text { molecular Engineering }\end{array}$ & 2227 & 1.70 & 29647 & 13.31 & 65 \\
\hline 2 & Kumar, S. & $\begin{array}{l}\text { Indian of Technology, } \\
\text { Chemical Engineering, } \\
\text { Gandhinagar }\end{array}$ & 1674 & 1.28 & 19748 & 11.8 & 52 \\
\hline 3 & Ghosh, S. & $\begin{array}{l}\text { Indian Institute Science, } \\
\text { Bengaluru }\end{array}$ & 1253 & 0.96 & 16984 & 13.55 & 51 \\
\hline 4 & Singh, S. & $\begin{array}{l}\text { National Institute of } \\
\text { Pharmaceutical } \\
\text { Education and Research, } \\
\text { Mohali }\end{array}$ & 1121 & 0.85 & 12222 & 10.9 & 45 \\
\hline 5 & Kumar, R. & $\begin{array}{l}\text { Guru Jambheshwar } \\
\text { University, Haryana }\end{array}$ & 1101 & 0.84 & 15068 & 13.69 & 51 \\
\hline 6 & Yadav, J. S. & $\begin{array}{l}\text { Indian Institute of } \\
\text { Chemical Technology, } \\
\text { Hyderabad }\end{array}$ & 914 & 0.70 & 17521 & 19.17 & 54 \\
\hline 7 & Das, S. & $\begin{array}{l}\text { Indian Institute of } \\
\text { Technology, Uttar } \\
\text { Pradesh }\end{array}$ & 897 & 0.68 & 11881 & 13.25 & 45 \\
\hline 8 & Singh, A. K. & $\begin{array}{l}\text { Indian Institute of } \\
\text { Technology, Uttar } \\
\text { Pradesh }\end{array}$ & 845 & 0.64 & 11457 & 13.56 & 46 \\
\hline 9 & Kumar, P. & $\begin{array}{l}\text { Centre for Development } \\
\text { of Advanced Computing, } \\
\text { Pune }\end{array}$ & 804 & 0.61 & 9524 & 11.85 & 41 \\
\hline 10 & Kumar, V. & $\begin{array}{l}\text { Polymer Research } \\
\text { Laboratory, Govt. } \\
\text { Autonomous Science } \\
\text { College, Jabalpur }\end{array}$ & 760 & 0.58 & 9642 & 12.69 & 41 \\
\hline 11 & Sharma, S. & $\begin{array}{l}\text { Indian Institute Science, } \\
\text { Bengaluru }\end{array}$ & 719 & 0.55 & 6784 & 9.44 & 33 \\
\hline 12 & Roy, S. & $\begin{array}{l}\text { Indian Institute of } \\
\text { Petroleum, Dehra Dun }\end{array}$ & 698 & 0.53 & 8908 & 12.76 & 43 \\
\hline 13 & Kumar, M. & $\begin{array}{l}\text { Gauhati University, } \\
\text { Assam }\end{array}$ & 677 & 0.52 & 9944 & 14.69 & 46 \\
\hline 14 & Sharma, A. & $\begin{array}{l}\text { National Chemical } \\
\text { Laboratory, Pune }\end{array}$ & 663 & 0.51 & 8730 & 13.17 & 42 \\
\hline 15 & Singh, A. & $\begin{array}{l}\text { Guru Nanak Dev } \\
\text { University, Punjab }\end{array}$ & 625 & 0.48 & 6058 & 9.69 & 28 \\
\hline 16 & Singh, P. & $\begin{array}{l}\text { Indian Institute } \\
\text { Technology, Kanpur }\end{array}$ & 615 & 0.47 & 6995 & 11.37 & 35 \\
\hline 17 & Das, D. & & 594 & 0.45 & 8671 & 14.6 & 44 \\
\hline 18 & Ghosh, A. & $\begin{array}{l}\text { Indian Institute Science, } \\
\text { Bengaluru }\end{array}$ & 585 & 0.45 & 9290 & 15.88 & 46 \\
\hline 19 & Reddy, B. V. S. & IIT, Korgpur & 578 & 0.44 & 11101 & 19.21 & 49 \\
\hline 20 & Pal, S. & $\begin{array}{l}\text { Indian Institute of } \\
\text { Chemical Technology, } \\
\text { Hyderabad }\end{array}$ & 574 & 0.44 & 7444 & 12.97 & 36 \\
\hline 21 & Kumar, D. & $\begin{array}{l}\text { Birla Institute } \\
\text { Technology \& Science, } \\
\text { Pilani }\end{array}$ & 573 & 0.44 & 6764 & 11.8 & 36 \\
\hline 22 & Singh, N. & $\begin{array}{l}\text { Guru Nanak Dev } \\
\text { University, Punjab }\end{array}$ & 569 & 0.43 & 8975 & 15.77 & 45 \\
\hline 22 & Banerjee, S. & $\begin{array}{l}\text { National Chemical } \\
\text { Laboratory, Pune }\end{array}$ & 569 & 0.43 & 8036 & 14.12 & 38 \\
\hline 23 & Singh, B. & $\begin{array}{l}\text { Indian Institute of } \\
\text { Technology, Kanpur }\end{array}$ & 551 & 0.42 & 6146 & 11.15 & 38 \\
\hline 24 & Sarkar, S. & $\begin{array}{l}\text { Centre for DNA } \\
\text { Fingerprinting and } \\
\text { Diagnostics, Hyderabad }\end{array}$ & 537 & 0.41 & 6960 & 12.96 & 37 \\
\hline 25 & Bhattacharya, S. & $\begin{array}{l}\text { Jadavpur University, } \\
\text { Kolkata }\end{array}$ & 534 & 0.41 & 8881 & 16.63 & 42 \\
\hline
\end{tabular}

The top 25 scientists from Indian chemical science research listed for their highest productivity are shown in Table 4 . These 25 scientists have together contributed 21,257 papers in India's cumulative publications output with an average of 817.58 papers per scientist. According to highest publications Kumar, A, occupies first rank with 2,227 articles $(29,647$ citations) with 13.31 of aveage citations per paper and his h-index is 65 , followed by Kumar, S. published 1,674 papers and received 19,748 citations with an average of 11.8 and his h-index is 52 , Ghosh, S. published 1,253 papers $(16,984$ citations), Singh, S. produced 1,121 papers and received 12,222 citations (h-index 45), Kumar, R. published 1,101 articles and received 15,068 citations. Yadav, J. S. has published 914 articles and received 17,521 citations with an average of 19.17 and his h-index is 54 and Das, S. published 897 articles.

\subsection{Channels Used for Communicating Cheimical Science Research}

Table 5 lists the channels used for communicating of Chemical science research include articles published in the journals, reviews, conference and seminars proceedings, editorial materials, corrections and book 
chapters. This study has observed a total of 1,31,221 publications in chemical science from India It has been observed from the table there are many communicating channels are used by scientists to publish their research articles in Indian chemical science literature. The majority of publications are published in Journals i.e. 1,22,712 (95.62), followed by Reviews 3,150 (2.40\%) publications, 2,692 (2.05\%) of papers published in Proceedings, 1,317 are as published as meeting abstracts and less than $1 \%$ of articles are published in other communication channels.

Table 5 Channels used for communicating cheimical science research

\begin{tabular}{llll}
\hline Sl. No. & Document Types & TP & \% of 131221 \\
\hline 1 & Article & 122712 & 95.62 \\
2 & Review & 3150 & 2.40 \\
3 & Proceedings Paper & 2692 & 2.05 \\
4 & Meeting Abstract & 1317 & 1.00 \\
5 & Editorial Material & 525 & 0.40 \\
6 & Correction & 506 & 0.39 \\
7 & Letter & 185 & 0.14 \\
8 & Book Chapter & 47 & 0.04 \\
9 & Biographical Item & 36 & 0.03 \\
10 & Retracted Publication & 27 & 0.02 \\
11 & Software Review & 11 & 0.01 \\
12 & News Item & 7 & 0.01 \\
13 & Retraction & 3 & 0.00 \\
14 & Reprint & 2 & 0.00 \\
15 & Book Review & 1 & 0.00 \\
\hline
\end{tabular}

\subsection{Language-Wise Distribution of Publications}

Table 6 provides the language-wise distribution of publications, the scientists researchers from Indian chemical science are published in different languages; English, Chinese, Japanese, German, Welsh, French, Estonian and Danish. It is observed that the majority $(99.98 \%)$ of articles published in english language, $0.008 \%$ articles published in chinese language and very less number of articles are published in remaining languages.

Table 6 Language-wise distribution of publications

\begin{tabular}{llll}
\hline Sl. No. & Languages & Records & \% of 131221 \\
\hline 1 & English & 131202 & 99.987 \\
2 & Chinese & 10 & 0.008 \\
3 & Japanese & 3 & 0.002 \\
4 & German & 2 & 0.002 \\
5 & Welsh & 1 & 0.001 \\
6 & French & 1 & 0.001 \\
7 & Estonian & 1 & 0.001 \\
8 & Danish & 1 & 0.001 \\
\hline
\end{tabular}

\subsection{Organizational/Institutional Collaboration}

Table 7 reveals the ranking list of top 25 highly productive Research Institutions in India based on their highest publications, citations, average citations per publication and h-index. According to the web of science database Indian Institute of Technology (IIT), Delhi contributed the highest publications to the field of engineering, i.e. 13,297 publications, followed by Bhabha Atomic Research Centre published 4.02 \% i.e. 5,273 articles and received 1,00,899 citations with an average (average citations per paper) 19.14 and h-index is 102, Indian Institute of Chemical Technology produced 5,078 papers and received 61,095 citations next to this Indian Institute of Science published $3.73 \%$ of papers $(4,888$ papers and received 1,04,872 citations), National Chemical Laboratory published 3,992 papers University of Delhi produced 3,373 articles and received 63,109 citations and average citations per paper is 18.71, Banaras Hindu University produced 3,306 articles and received 61,905 citations and University of Hyderabad published 3,008 papers with 16.08 average citations per paper.

Table 7 Organizational/Institutional collaboration

\begin{tabular}{|c|c|c|c|c|c|c|}
\hline $\begin{array}{l}\text { Sl. } \\
\text { No. }\end{array}$ & Organizations & TP & TC & ACP & $\begin{array}{l}\mathrm{H}- \\
\text { index }\end{array}$ & $\%$ \\
\hline 1 & Indian Institute of Technology & 13297 & & & & 10.13 \\
\hline 2 & Bhabha Atomic Research Centre & 5273 & 100899 & 19.14 & 102 & 4.02 \\
\hline 3 & $\begin{array}{l}\text { Indian Institute of Chemical } \\
\text { Technology }\end{array}$ & 5078 & 61095 & 12.03 & 79 & 3.87 \\
\hline 4 & Indian Institute of Science & 4888 & 104872 & 21.45 & 113 & 3.73 \\
\hline 5 & National Chemical Laboratory & 3992 & 85250 & 21.36 & 103 & 3.04 \\
\hline 6 & University of Delhi & 3373 & 63109 & 18.71 & 88 & 2.57 \\
\hline 7 & Banaras Hindu University & 3306 & 61905 & 18.73 & 88 & 2.52 \\
\hline
\end{tabular}

https://doi.org/10.30799/jacs.178.18040101

\begin{tabular}{|c|c|c|c|c|c|c|}
\hline 8 & University of Hyderabad & 3008 & 48361 & 16.08 & 72 & 2.29 \\
\hline 9 & University of Calcutta & 2845 & 50596 & 17.78 & 84 & 2.17 \\
\hline 10 & National Institute of Technology & 2806 & 40332 & 14.37 & 71 & 2.14 \\
\hline 11 & Aligarh Muslim University & 2697 & 48244 & 17.89 & 81 & 2.06 \\
\hline 12 & Anna University & 2480 & 35230 & 14.21 & 70 & 1.89 \\
\hline 13 & $\begin{array}{l}\text { Jawaharlal Nehru Centre for } \\
\text { Advance Science Research }\end{array}$ & 2423 & 38147 & 15.74 & 74 & 1.85 \\
\hline 14 & Guru Nanak Dev University & 2132 & 26736 & 12.54 & 55 & 1.62 \\
\hline 15 & Panjab University & 2127 & 44319 & 20.84 & 82 & 1.62 \\
\hline 16 & University of Rajasthan & 1844 & 21229 & 11.51 & 55 & 1.41 \\
\hline 17 & University of Madras & 1836 & 27524 & 14.99 & 64 & 1.40 \\
\hline 18 & Annamalai University & 1603 & 50581 & 31.55 & 96 & 1.22 \\
\hline 19 & Shivaji University & 1577 & 37419 & 23.73 & 90 & 1.20 \\
\hline 20 & University of Allahabad & 1556 & 21176 & 13.61 & 59 & 1.19 \\
\hline 21 & Central Drug Research Institute & 1461 & 15184 & 10.39 & 44 & 1.11 \\
\hline 22 & Institute of Chemical Technology & 1440 & 19515 & 13.55 & 58 & 1.10 \\
\hline 22 & $\begin{array}{l}\text { Indian Institute of Technology } \\
\text { Guwahati }\end{array}$ & 1342 & 23742 & 17.69 & 60 & 1.02 \\
\hline 23 & Osmania University & 1280 & 18435 & 14.4 & 58 & 0.98 \\
\hline 24 & Sri Venkateswara University & 1265 & 12981 & 10.26 & 39 & 0.96 \\
\hline 25 & University of Kalyani & 1247 & 19268 & 15.45 & 58 & 0.95 \\
\hline
\end{tabular}

\subsection{Subject-Wise Productivity of Indian Chemical Science Research}

Table 8 indicate the subject-wise productivity of India in chemical science research. Materials Science, Biochemistry Molecular Biology, Science Technology Other Topics, Pharmacology Pharmacy, Engineering, Electrochemistry, Crystallography, Metallurgy Metallurgical Engineering, Polymer Science, Food Science Technology, Thermodynamics, Energy Fuels, Nuclear Science Technology, Biophysics, Instruments Instrumentation, Environmental Sciences Ecology were considered on the basis of the total number of publications.

Table 8 Subject-wise productivity of Indian chemical science research

\begin{tabular}{|c|c|c|c|c|c|c|}
\hline $\begin{array}{l}\text { Sl. } \\
\text { No. }\end{array}$ & Research Areas & TP & $\begin{array}{l}\% \text { of } \\
131221\end{array}$ & $\mathrm{TC}$ & ACP & $\begin{array}{l}\text { H- } \\
\text { index }\end{array}$ \\
\hline 1 & Materials Science & 16316 & 12.434 & --- & --- & $\begin{array}{ll}--- \\
\end{array}$ \\
\hline 2 & $\begin{array}{l}\text { Biochemistry Molecular } \\
\text { Biology }\end{array}$ & 6922 & 5.275 & 89357 & 12.91 & 92 \\
\hline 3 & $\begin{array}{l}\text { Science Technology Other } \\
\text { Topics }\end{array}$ & 6891 & 5.251 & 121545 & 17.64 & 119 \\
\hline 4 & Pharmacology Pharmacy & 5619 & 4.282 & 90529 & 16.11 & 97 \\
\hline 5 & Engineering & 5593 & 4.262 & 69934 & 12.5 & 90 \\
\hline 6 & Electrochemistry & 3888 & 2.963 & 74479 & 19.16 & 90 \\
\hline 7 & Crystallography & 3623 & 2.761 & 54103 & 14.93 & 72 \\
\hline 8 & $\begin{array}{l}\text { Metallurgy Metallurgical } \\
\text { Engineering }\end{array}$ & 2950 & 2.248 & 36214 & 12.28 & 57 \\
\hline 9 & Polymer Science & 2791 & 2.127 & 48148 & 17.25 & 79 \\
\hline 10 & Food Science Technology & 2750 & 2.096 & 42802 & 15.56 & 78 \\
\hline 11 & Thermodynamics & 2429 & 1.851 & 25652 & 10.56 & 49 \\
\hline 12 & Energy Fuels & 2160 & 1.646 & 41837 & 19.37 & 75 \\
\hline 13 & Nuclear Science Technology & 1958 & 1.492 & 11682 & 5.97 & 32 \\
\hline 14 & Biophysics & 1741 & 1.327 & 37336 & 21.45 & 73 \\
\hline 15 & $\begin{array}{l}\text { Instruments } \\
\text { Instrumentation }\end{array}$ & 1396 & 1.064 & 27375 & 19.61 & 69 \\
\hline 16 & $\begin{array}{l}\text { Environmental Sciences } \\
\text { Ecology }\end{array}$ & 1226 & 0.934 & 18645 & 15.21 & 62 \\
\hline 17 & Agriculture & 1164 & 0.887 & 13693 & 11.76 & 48 \\
\hline 18 & Spectroscopy & 922 & 0.703 & 7629 & 8.27 & 33 \\
\hline 19 & Nutrition Dietetics & 761 & 0.58 & 20090 & 26.4 & 64 \\
\hline 20 & Computer Science & 722 & 0.55 & 8002 & 11.08 & 36 \\
\hline 21 & Plant Sciences & 680 & 0.518 & 4186 & 6.16 & 27 \\
\hline 22 & $\begin{array}{l}\text { Biotechnology Applied } \\
\text { Microbiology }\end{array}$ & 655 & 0.499 & 15135 & 23.11 & 55 \\
\hline 22 & Mathematics & 463 & 0.353 & 3750 & 8.1 & 25 \\
\hline 23 & $\begin{array}{l}\text { Radiology Nuclear Medicine } \\
\text { Medical Imaging }\end{array}$ & 324 & 0.247 & 2321 & 7.16 & 21 \\
\hline 24 & Toxicology & 310 & 0.236 & 2778 & 8.96 & 25 \\
\hline 25 & Acoustics & 287 & 0.219 & 6561 & 22.86 & 43 \\
\hline
\end{tabular}

\subsection{High Productive Subject Areas in Chemical Science (World and India)}

Table 9 provides the observation from the table Pharmacology Pharmacy, Electrochemistry and Crystallography have been identified as the three high priority research areas of Indian chemical science with each contributing publication share $4.28 \%, 2.96 \%$ and $2.77 \%$ in the national publication output during 2002-2016. High productive subject areas in chemical science Pharmacology Pharmacy had increased from 1,380 publications during 2002-2006 to 2,036 publications during 2007-2011, 
and 2,203 publications during 2012-2016, Electrochemistry had increased from 544 publications during 2002-2006 to 1,210 publications during 2007-2011, and 2,134 publications during 2012-2016 and Crystallography had increased from 733 publications during 2002-2006 to 1,107 publications during 2007-2011, and 1,792 publications during 2012-2016. With regard to world Pharmacology Pharmacy, Electrochemistry and Energy Fuels are identified as the three high priority areas of world's chemical science research.

Table 9 High Productive Subject Areas in chemical science (World and India)

Highest Productive Sub-fields in Indian Chemical Science Literature

\begin{tabular}{llllllll}
\hline \multicolumn{7}{l}{ Highest Productive Sub-fields in Indian Chemical Science Literature } \\
\hline
\end{tabular}

Table 10 Medium Productive Subject Areas in chemical science (World and India)

Medium Productive Sub-fields in Indian Chemical Science Literature

\begin{tabular}{|c|c|c|c|c|c|c|c|c|c|c|c|c|}
\hline \multirow[b]{2}{*}{ Year } & \multicolumn{3}{|c|}{ Polymer Science } & \multicolumn{3}{|c|}{ Thermodynamics } & \multicolumn{3}{|c|}{ Energy Fuels } & \multicolumn{3}{|c|}{ Nuclear Science Technology } \\
\hline & $\mathrm{TP}$ & $\mathrm{TC}$ & ACPP & $\mathrm{TP}$ & $\mathrm{TC}$ & ACPP & $\mathrm{TP}$ & $\mathrm{TC}$ & ACPP & $\mathrm{TP}$ & $\mathrm{TC}$ & ACPP \\
\hline $2002-2006$ & 328 & 11664 & 35.56 & 450 & 8761 & 19.47 & 232 & 8136 & 35.07 & 420 & 4549 & 10.83 \\
\hline $2007-2011$ & 605 & 18684 & 30.88 & 803 & 10350 & 12.89 & 588 & 17284 & 29.39 & 547 & 4394 & 8.03 \\
\hline 2012-2016 & 1858 & 18422 & 9.91 & 1176 & 6851 & 5.83 & 1340 & 17153 & 12.80 & 991 & 2860 & 2.89 \\
\hline 2002-2016 & 2791 & 48770 & 17.47 & 2429 & 25962 & 10.69 & 2160 & 42573 & 19.71 & 1958 & 11803 & 6.03 \\
\hline \multicolumn{13}{|c|}{ Medium Productive Sub-fields in World Chemical Science Literature } \\
\hline & \multicolumn{3}{|c|}{ Crystallography } & \multicolumn{3}{|c|}{ Polymer Science } & \multicolumn{3}{|c|}{ Thermodynamics } & \multicolumn{3}{|c|}{ Instruments Instrumentation } \\
\hline Year & $\mathrm{TP}$ & TC & ACPP & $\mathrm{TP}$ & TC & ACPP & $\mathrm{TP}$ & $\mathrm{TC}$ & ACPP & $\mathrm{TP}$ & $\mathrm{TC}$ & ACPP \\
\hline $2002-2006$ & 10441 & 223813 & 21.44 & 6473 & 228545 & 35.31 & 9061 & 165260 & 18.24 & 5726 & 141702 & 24.75 \\
\hline $2007-2011$ & 15175 & 339954 & 22.40 & 11920 & 352206 & 29.55 & 11775 & 159345 & 13.53 & 10282 & 193711 & 18.84 \\
\hline 2012-2016 & 19732 & 155256 & 7.87 & 20415 & 207420 & 10.16 & 13997 & 73639 & 5.26 & 17261 & 133382 & 7.73 \\
\hline $2002-2016$ & 45348 & 719023 & 15.86 & 38808 & 788171 & 20.31 & 34833 & 398244 & 11.43 & 33269 & 468795 & 14.09 \\
\hline
\end{tabular}

Table 11 Low Productive Subject Areas in chemical science (World and India)

Low Productive Sub-fields in Indian Chemical Science Literature

\begin{tabular}{|c|c|c|c|c|c|c|c|c|c|}
\hline \multirow[b]{2}{*}{ Year } & \multicolumn{3}{|c|}{ Instruments Instrumentation } & \multicolumn{3}{|c|}{ Spectroscopy } & \multicolumn{3}{|c|}{ Toxicology } \\
\hline & $\mathrm{TP}$ & TC & ACPP & $\mathrm{TP}$ & $\mathrm{TC}$ & ACPP & $\mathrm{TP}$ & $\mathrm{TC}$ & ACPP \\
\hline $2002-2006$ & 184 & 7041 & 38.27 & 135 & 1812 & 13.42 & 67 & 945 & 14.10 \\
\hline 2007-2011 & 416 & 11115 & 26.72 & 264 & 2952 & 11.18 & 94 & 1209 & 12.86 \\
\hline 2012-2016 & 796 & 10663 & 13.40 & 523 & 2979 & 5.70 & 149 & 682 & 4.58 \\
\hline 2002-2016 & 1396 & 28819 & 20.64 & 922 & 7743 & 8.40 & 310 & 2836 & 9.15 \\
\hline \multicolumn{10}{|c|}{ Low Productive Sub-fields in World Chemical Science Literature } \\
\hline & \multicolumn{3}{|c|}{ Spectroscopy } & \multicolumn{3}{|c|}{ Nuclear Science Technology } & \multicolumn{3}{|c|}{ Toxicology } \\
\hline Year & $\mathrm{TP}$ & TC & ACPP & TP & TC & ACPP & $\mathrm{TP}$ & TC & ACPP \\
\hline $2002-2006$ & 8681 & 216067 & 24.89 & 5684 & 57659 & 10.14 & 3579 & 74573 & 20.84 \\
\hline 2007-2011 & 10041 & 179785 & 17.91 & 6071 & 49272 & 8.12 & 3864 & 62036 & 16.05 \\
\hline 2012-2016 & 14451 & 83019 & 5.74 & 8149 & 23947 & 2.94 & 3997 & 23618 & 5.91 \\
\hline 2002-2016 & 33173 & 478871 & 14.44 & 19904 & 130878 & 6.58 & 11440 & 160227 & 14.01 \\
\hline
\end{tabular}

\subsection{Medium Productive Subject Areas in Chemical Science (World and India)}

Table 10 deals that Polymer Science, Thermodynamics, Energy Fuels and Nuclear Science Technology have been identified as the medium productive subject areas of Indian chemical science with each contributing publication share $2.13 \%, 1.85 \%, 1.65 \%$ and $1.49 \%$ in the national publication output during 2002-2016. Medium productive subject areas in chemical science Polymer Science had increased from 328 publications during 2002-2006 to 605 publications during 2007-2011, and 1,858 publications during 2012-2016, Thermodynamics had increased from 450 publications during 2002-2006 to 803 publications during 2007-2011 and 1,176 publications during 2012-2016, Energy Fuels had increased from 232 publications during 2002-2006 to 588 publications during 2007-2011 and 1,340 publications during 2012-2016 and Nuclear Science Technology had increased from 420 publications during 2002-2006 to 547 publications during 2007-2011, and 991 publications during 2012-2016. In the same manner in world's chemical science literature Crystallography (1.89\% of total output), Polymer Science (1.61\%), Thermodynamics $(1.45 \%)$ and Instruments Instrumentation (1.38\%) subjects are identified as the medium productive sub-fields.

\subsection{Low Productive Subject Areas in chemical science (World and India)}

Table 11 reveals that Instruments Instrumentation, Spectroscopy, Toxicology have been identified as the low productive subject areas of https://doi.org/10.30799/jacs.178.18040101
Indian chemical science with each contributing publication share $1.06 \%$, $0.70 \%$ and $0.24 \%$ in the national publication output during 2002-2016. Low productive subject areas in chemical science Instruments Instrumentation had increased from 184 publications during 2002-2006 to 416 publications during 2007-2011, and 796 publications during 20122016, Spectroscopy had increased from 135 publications during 20022006 to 264 publications during 2007-2011 and 523 publications during 2012-2016 and Toxicology had increased from 67 publications during 2002-2006 to 94 publications during 2007-2011, and 149 publications during 2012-2016. Spectroscopy, Nuclear Science Technology and Toxicology are the three low productive subject fields in world's chemical science literature.

\subsection{International Collaboration}

Due to the interdisciplinary growth of subject, the universe of knowledge is ever dynamic and is ever-growing. More and more specialization in the subjects is achieved by the scientists, which is a result of increased participation of group of researchers of different expertise. It has been found from earlier studies that collaboration in research varies from discipline to discipline and for the same discipline from time to time and from one country to another [11].

Collaborative research has become a well established feature in the field of chemical science. It is observed that there is a consistently increasing 
trend towards collaboration among various branches of chemical science which leads to collaborative authorship in literature.

Table 12 International Collaboration

\begin{tabular}{llll}
\hline Sl. No. & Countries & TP & \% of 131221 \\
\hline 1 & USA & 5255 & 4.005 \\
2 & Germany & 2597 & 1.979 \\
3 & South Korea & 2461 & 1.875 \\
4 & Japan & 2062 & 1.571 \\
5 & England & 1549 & 1.18 \\
6 & France & 1484 & 1.131 \\
7 & Spain & 1224 & 0.933 \\
8 & Saudi Arabia & 1188 & 0.905 \\
9 & Italy & 1040 & 0.793 \\
10 & Taiwan & 1028 & 0.783 \\
11 & Canada & 777 & 0.592 \\
12 & Peoples R China & 699 & 0.533 \\
13 & Australia & 691 & 0.527 \\
14 & Malaysia & 663 & 0.505 \\
15 & South Africa & 545 & 0.415 \\
16 & Switzerland & 433 & 0.33 \\
17 & Singapore & 400 & 0.305 \\
18 & Portugal & 396 & 0.302 \\
19 & Poland & 342 & 0.261 \\
20 & Belgium & 322 & 0.245 \\
21 & Czech Republic & 302 & 0.23 \\
22 & Sweden & 301 & 0.229 \\
23 & Iran & 276 & 0.21 \\
24 & Israel & 275 & 0.21 \\
25 & Scotland & 274 & 0.209 \\
\hline & & &
\end{tabular}

Table depicts the international collaborative papers of India with top with 25 countries during 2002-2016. The share of International collaborative publications in the Indian chemical science research output was $20.26 \%$ during 2002-2016. The largest number of collaborative publications $(5,255)$ of India in chemical science research was with United States with $4.005 \%$ share, followed by Germany contributed 2,597 papers with $1.979 \%$ of total share, South Korea published 2,461 papers, Japan produced 2,062 papers, England published 1,549 articles, France contributes 1,484 papers, Spain published 1,224 papers and Saudi Arabia has contributed with India in chemical science research i.e. 1,188 papers. Many countries are contributed with below $1 \%$ share with India in chemical science research during 2002 to 2016 (Table 12).

\section{Conclusion}

The analysis of chemical science has finds the publications share of India during 2002-2016 was 5.46\%, which has increased from 3.94 in 2002 to 6.99 in 2016 and it is observed from the study that the percentage of India's papers compared to that of the world's papers. India's share of science and technology research output increased from $3.94 \%$ in 2002 to $6.99 \%$ in 2016 . Scientometric studies enable the science policy makers and administrators to understand and grasp the growth, development and impact of research and to know the countries, institutions and the individual scientists who are active in a particular field of research activity. These studies will also provide some insights into the dynamics of research activity and enable one to gauge the direction of research activity and take appropriate measures.

Considering the above facts; it may be concluded that there is variation from one discipline to different periods, form one region to another. The collaboration in research is affected by various socio - economic and the other environmental factors prevailing in a specific society. Hence it is proposed further research be conducted to study the nature of collaborative output of different subject areas in science, social science and humanities. The investigations of such nature may be found useful in understanding the research and communication patterns for Indian Chemical Science. The observing study will be helpful in planning more effective research and communication systems.

\section{Acknowledgement}

The authors thank to the Head of the Department of Library \& Information Science, Karnataka University, Dharwad and Dr. Vitthal Bagalkoti for providing necessary facilities and resources for completing this article.

\section{References}

[1] C. Velmurugan, N. Radhakrishnan, Webology journal: a scientometric profile, Int. Jour. Inform. Dissem. Technol. 5(2) (2015) 137-142.

[2] J.K. Singh, A bibliometric analysis of LIBRI Journal (2001-2009), Ind. Jour. Inform. Sources Services 2(1) (2012). 55-60.

[3] I. Khan, A Scientometric analysis of DESIDOC, Jour. Lib. Inform. Technol. (20102014), Library Hi Tech News 33(7) (2016) 8-12.

[4] L. Lu, R. Perdisci, W. Lee, Surf: detecting and measuring search poisoning In Proceedings of the 18th ACM conference on Computer and communications security, Georgia Institute of Technology, USA, 2011, pp. 467-476

[5] C. Velmurugan, Bibliometric analysis with special reference to authorship pattern and collaborative research output of annals of library and information studies for the Year 2007-2012, Int. Jour. Digital Lib. Services 3(3) (2013) 1321.

[6] S. Thanuskodi, Journal of social sciences: A bibliometric study, Jour. Social Sci. 24(2) (2010) 77-80.

[7] Kumara, Anil, Bibliometric and scientometric studies in physics and engineering: recent ten years analysis, In Putting Knowledge to Work: Best Practices in Librarianship, Mumbai, India, 2009.

[8] J. Guan, N. Ma, A Bibliometric study of China's Semiconductor Literature compared with other major Asian countries, Scientometric 70(1) (2007) 107124.

[9] S.K. Patra, P. Bhattacharya, N. Verma, Bibliometric study of literature on bibliometrics, DESIDOC Bull. Inform. Technol. 26(1) (2006) 27-32.

[10] B.U. Kannappanavar, C. Swamy, M. Vijay Kumar, Publishing trend of indian chemical scientists: A Bibliometric Study, Annal. Lib. Inform. Stud. 51(1) (2004) 39-41.

[11] S.L. Sangam, Meera, M.N. Megeri, Growth pattern of Indian Chemical Science literature: A Scientometric analysis, COLLNET Jour. Scientomet. Inform. Manag. 2(1) (2008) 99-110. 